\title{
Erratum to: Correlations between petrographic and geometrical properties of ophiolitic aggregates from Greece
}

\author{
Ioannis Rigopoulos • Basilios Tsikouras • \\ Panagiotis Pomonis - Konstantin Hatzipanagiotou
}

Published online: 9 November 2014

(c) Springer-Verlag Berlin Heidelberg 2014

\section{Erratum to: Bull Eng Geol Environ (2014) 73:1-12 DOI 10.1007/s10064-013-0486-3}

The authors would like to draw attention to editorial errors occurring in the original publication.

1. Replace the whole Sect. "Introduction" from pages 1 and 2 with:

\section{Introduction}

Ophiolitic complexes are among the most important sources of aggregates as they include lithotypes with good engineering properties. They are remnants of the Earth's oceanic crust and upper mantle, derived from mid-ocean ridges or marginal basins. A complete ophiolite suite consists from

The online version of the original article can be found under doi:10.1007/s10064-013-0486-3.

\author{
I. Rigopoulos $(\bowtie) \cdot$ B. Tsikouras · K. Hatzipanagiotou \\ Department of Geology, Section of Earth Materials, University \\ of Patras, 26500 Patras, Greece \\ e-mail: rigopoul@upatras.gr \\ B. Tsikouras \\ e-mail: v.tsikouras@upatras.gr \\ K. Hatzipanagiotou \\ e-mail: k.hatzipanagiotou@upatras.gr \\ B. Tsikouras \\ University of Brunei Darussalam, Department of Petroleum \\ Geoscience, Jalan Tungku Link, Gadong, \\ BE1410 Bandar Seri Begawan, Brunei Darussalam \\ P. Pomonis \\ Department of Geology and Geoenvironment, University of \\ Athens, 15784 Athens, Greece \\ e-mail: ppomonis@geol.uoa.gr
}

bottom to top of ultrabasic, basic, hypabyssal and extrusive rocks. Ocean-floor metamorphism usually obscures primary petrographic characteristics of ophiolitic rocks, leading to a modification of their strength properties (e.g. Ramana et al. 1986; Marinos et al. 2006; Rigopoulos et al. 2010).

Aggregate particle shape appears to be a major determinant for the quality of aggregates, as it affects the properties of mixtures (Kaplan 1958; Bloem and Gaynor 1963). The effects of particle shape on the properties of both fresh and hardened concrete tend to be beneficial where the predominant shape is generally equidimensional and detrimental when it is flaky and/or elongated (Kaplan 1958, 1959; Neville 1995). As the proportion of flat particles in hydraulic concrete increases, the compression strength decreases, the cement consumption increases and the workability decreases (Frazao and Sbrighi Neto 1984).

The shape characteristics of aggregates reflect intrinsic petrographic properties, together with production factors. Thus, petrography is of fundamental importance in understanding the geometrical properties of rocks; its use in the evaluation of aggregates dates back to the early part of the 20th century (Knight and Knight 1935; Rhoades and Mielenz 1946). The engineering parameters of rocks are a function of their mineralogy, texture, degree of chemical alteration, weathering and deformation (Hartley 1974; Ákesson et al. 2001; Zorlu et al. 2004; Rigopoulos et al. 2011).

As previously noted, ophiolitic complexes include a significant variety of lithotypes, which are often modified by hydrothermal metamorphism and tectonic deformation. Consequently, these suites commonly present a wide range of petrographic features and thus the existence of lithotypes with variable geometrical properties is very common, even in the same suite. It is generally recognised that aggregate shape significantly depends on the rock type and its microscopic characteristics, but only a few studies have 
been published on this subject (Miskovsky et al. 2004). Given this paucity of technical data, this study aims at investigating the effect of mineralogical and textural characteristics on aggregate shape and especially the relationships between the geometrical properties and specific petrographic parameters. An evaluation of the properties of the studied samples as aggregate material is also attempted, along with an assessment of their in-service performance.

2. Omit the word "former" from line 4, page 2, right column, in Sect. "Geological setting".

3. Replace the sentence in lines 14-16 of the second paragraph, left column, page 4 (Sect. "Petrography"), with:

The deformation of these samples is primarily brittle, as indicated by the numerous intragranular and transgranular microcracks.

4. Replace "honeycombed-and-porous" in the last two lines of the first paragraph in Sect. "Surface texture", page 4, with "honeycombed and porous".

5. Replace the first sentence (first 4 lines) of the first paragraph in Sect. "Discussion", page 8, with:

The petrographic analysis outlined above, indicates that the studied ophiolitic rocks have been variably affected by ocean-floor alteration processes.

6. Replace "gives" from the eleventh line, second paragraph in Sect. "Discussion", page 8, with "give".

7. Replace the first line, left column, page 9, with: The micro-roughness of aggregate particles.

8. Replace the sentence in lines 5-9 of the second paragraph, left column, page 10, with: The modification of the mineralogical and textural characteristics of the studied rock types by hydrothermal metamorphism is considered to be the reason for the deterioration of their geometrical properties.

9. Replace the whole Sect. "Conclusions" (page 11) with:

\section{Conclusions}

This study has highlighted the usefulness of petrographic analysis for the interpretation of the geometrical parameters of ultrabasic and basic ophiolitic aggregates. The rocks investigated from the Pindos, Vourinos and Koziakas ophiolites include dunites, olivine-rich harzburgites, typical harzburgites, plagioclase-bearing lherzolites, troctolites and dolerites, each lithotype with various degrees of hydrothermal alteration.

Regression analysis established that ocean-floor metamorphism modifies the geometrical properties of ophiolitic rocks. The percentage of serpentine, the ratio of soft to hard minerals $\left(S_{o} / H\right)$ and the ratio of secondary to primary minerals $\left(S_{e} / P\right)$ were used in order to quantify the petrographic transformations which take place during the alteration processes. The replacement index $I_{\text {rep}}$, which indicates and quantifies the degree of replacement of the primary mafic minerals by secondary products as a result of ocean-floor metamorphism, has also been used in correlation analysis. The relationships between the above mentioned petrographic parameters and the geometrical properties indicate that the shape characteristics of ophiolitic aggregates tend to deteriorate with increasing degree of hydrothermal metamorphism. The flakiness and elongation indices are significantly affected by the degree of alteration of ophiolitic rocks, while the sand equivalent seems to be less influenced.

The higher flakiness and elongation index values of the ultrabasic samples compared to the basic ones are attributed to (1) the high percentage of serpentine, (2) the local preferred orientation of the olivine grains and (3) the presence of oriented transgranular microcracks in the former. The variation of the particle shape characteristics of ophiolite-derived aggregates is related to (1) the degree of preservation of the primary mineral phases, (2) the development of soft minerals during alteration and (3) the degree of tectonic deformation.

In view of the above, a petrographic examination is essential for the preliminary assessment of the geometrical properties of aggregates, which are of major significance for engineering design purposes. 